\title{
A Study on Tourism Development of Yinquan Homestay From Perspective of Tourists' Perception
}

\author{
Furong $\mathrm{Fu}^{*}$ \\ School of Economics and Management, Beijing Jiaotong University, China \\ *Corresponding author.Email:1908964842@qq.com
}

\begin{abstract}
In recent years, with the development of the experience economy, tourists continue to put forward new requirements. Especially in terms of accommodation, they are no longer satisfied with pure tourism accommodation products, but pay more attention to in-depth experience and feelings. Therefore, only when the homestay is based on its own advantages and disadvantages, intensified innovation, and tapping cultural connotation, can it bring a new experience to tourists and increase the tourist attraction and competitiveness of the homestay. In this paper, through the perspective of tourists' perception, using literature analysis, online interviews and questionnaires, the overall development status and existing problems of Yinquan homestay are researched, and it is concluded Publicity and marketing still have to work hard. This can not only provide a certain reference for the future development of Yinquan homestay in the future, but also attract more tourists to Jinan and enhance the tourist attraction of Jinan.
\end{abstract}

Keywords: Tourist perception, Yinquan homestay, Tourism development

\section{INTRODUCTION}

With the rapid development of my country's economy, the development of tourism is also advancing steadily, and tourists continue to put forward new requirements for tourism products. As one of the six elements of tourism activities, "living" is constantly developing and innovating. The development of homestays has met the needs of some tourists to a certain extent. This article uses literature analysis method, online interview method, questionnaire survey method, starting from the perspective of tourists' perception, taking Yinquan homestay as the object, and proposing the direction and ideas for the development of the homestay.

\section{LITERATURE REVIEW}

There are many researches on homestay at home and abroad. Nancy Awadallah Awad investigated the impact of information technology and customer relationship management practices on the performance of homestays, and suggested that homestays strengthen customer relationships, improve homestay performance and improve information technology, so that homestays can be more competitive in the industry[1]. Lu Huijuan and $\mathrm{Li}$ Xiang selected literature analysis method, network text analysis method and questionnaire method to investigate the Beijing Siheyuan homestay, and used IPA analysis method to analyze the collected data. Beijing Siheyuan not only has the function of accommodation, but also a business card to promote Beijing culture. In this regard, feasible suggestions are put forward: improve the tourist attraction of Beijing Siheyuan homestays by improving basic supporting facilities, enhancing cultural connotation, and innovating marketing models [2]. Taking Lichuan City, Hubei Province as an example, Lu Shiju and $\mathrm{Wu}$ Hailun conducted a field investigation and visit to the development of the homestay industry in Lichuan City. They summarized the experience of good operation of the homestay industry in the context of targeted poverty alleviation. And work hard on the unique cultural features of the homestay [3].

\section{HOMESTAY ANALYSIS PROCESS}

\subsection{Opportunities for Tourism Development of Yinquan Homestay}

Policy Support: The State Council continues to improve the policies and regulations for the development of homestays, and has issued relevant documents for many years to increase support for 
homestays. For example, the "Implementation Plan for Improving the Consumption Promotion Mechanism (2018-2020)" issued by the State Council encourages the development of tourism services such as homestays, homestays and inns. The introduction of policies promotes the legalization of homestays and vigorously develops leisure agriculture and homestay tourism. The development of homestays is escorted, and it is recommended that all localities establish reasonable and effective homestay industry management policies, establish a unified mechanism, and improve the standardization and stability of homestay operations [4].

Increased consumption demand and space of tourists: People are now busy in a "fast pace" life, and their hearts are longing for a "slow life" and "a leisurely life". With the increase of people's disposable income and the enhancement of consumption power, the demand and space for tourism consumption also increase. In 2017, Jinan received 72.856 million domestic tourists nationwide, an increase of $10.1 \%$, and achieved a total tourism consumption of 97.08 billion yuan, an increase of $14.6 \%$. People's demand for tourism is gradually increasing, and the requirements for "living" are also increasing. I hope that the place to live is more intimate, more comfortable and more personalized. In order to pursue a clean and comfortable modern accommodation, tourists are willing to spend on "living" money.

\subsection{Challenges of Tourism Development in Yinquan Homestay}

Fierce competition in domestic homestays: Tourists are paying more and more attention to the experience of tourism, especially in terms of "food", "living" and "tour". The emphasis on "living" has led to the rapid rise of domestic homestays, especially homestays in Zhejiang and Yunnan, which are quite popular among tourists. In recent years, the development of homestays has been too crazy. Whether in towns or in the countryside, a large number of homestays have emerged. The problem of homogeneity has become more and more obvious. Homestays are more like a commodity, lacking its proper features.

Competition from surrounding hotels: Jinan Yinquan homestay is located in the Quancheng Plaza business district, surrounded by several well-known branded hotels, such as Shangri-La Hotel, Sofitel Silver Plaza Hotel, Grand Metropark Qihui Hotel, etc., facing a complete set of star-rated hotels Facilities and standardized services. The Yinquan homestay alone relies on the words "warm", "spring culture", and "quiet in trouble", which is not enough to attract a large number of tourists. It still needs to improve infrastructure, service quality, personalized customization, etc. effort.

\subsection{Tourists' Perception of the Current Situation of Yinquan Homestay}

In order to more intuitively show the development status of Yinquan homestay tourism, this article adopts the method of questionnaire. The respondents are residents of Yinquan homestay. A total of 201 valid questionnaires were received. Among them, most of them are young and middle-aged, students and workers. This article mainly studies the tourism marketing, the improvement of supporting facilities and services, and the excavation of cultural connotations of Yinquan homestay from the perspectives of tourists' willingness to book, the reasons for choosing staying, the satisfaction of staying experience, the advantages and disadvantages of homestays.

Tourists' willingness to stay again: When choosing a homestay, tourists will largely pay attention to the reoccupancy rate of the homestay, because this data can show whether the homestay is worth staying in. In this questionnaire about Jinan Yinquan homestay tourism, we can see that $91.54 \%$ of tourists are willing to stay again.

Supporting facilities and services: In the operation of homestays, infrastructure and special services are very important. According to the survey, only $38.81 \%$ of the reasons for choosing to stay at Yinquan homestay think that the transportation is convenient, and in the feedback from the questionnaire, there are many times that no suitable parks can be found. The problem of parking places also shows that the infrastructure of Yinquan Residence is not perfect. Only $46.77 \%$ think the service is good and the owner is kind, indicating that the service quality of Yinquan homestay still needs to be improved.

Information access: The relevant information and welfare activities of the homestay can only be made known to tourists through publicity. According to the data from the questionnaire, $78.61 \%$ of tourists obtained homestay information and learned about homestays through online media. Thirdly, it was introduced by relatives and friends, while only $38.81 \%$ recommended by local residents, indicating that the publicity of Yinquan homestay is mainly online. There are fewer offline promotion methods. And $83.58 \%$ of the respondents believe that homestays should increase publicity. 
Table1. Questionnaire feedback

\begin{tabular}{|c|c|c|}
\hline Serial number & Time to submit answer sheet & Answer text \\
\hline 95 & February 27th at 08:35 & If there is a dedicated parking lot \\
\hline 102 & February 28th at 11;41 & Consider having a parking lot \\
\hline 129 & February 28th at 17:16 & $\begin{array}{c}\text { The surrounding traffic should be convenient and } \\
\text { convenient for parking }\end{array}$ \\
\hline 134 & February 28th at 18:17 & No place to park, hope it can be improved \\
\hline 209 & March 2 at 15:58 & Just have a dedicated parking lot \\
\hline
\end{tabular}

Table 2. Respondents believe that there are existing problems in Yinquan homestay

\begin{tabular}{|c|c|c|c|c|c|}
\hline Problems & $\begin{array}{c}\text { Service quality } \\
\text { needs to be } \\
\text { improved }\end{array}$ & $\begin{array}{c}\text { Room facilities } \\
\text { need to be } \\
\text { upgraded }\end{array}$ & $\begin{array}{c}\text { Increase } \\
\text { publicity }\end{array}$ & $\begin{array}{c}\text { Add more } \\
\text { entertainment }\end{array}$ & $\begin{array}{c}\text { Poor security and } \\
\text { privacy }\end{array}$ \\
\hline Proportion & $39.8 \%$ & $58.71 \%$ & $83.58 \%$ & $69.15 \%$ & $23.88 \%$ \\
\hline
\end{tabular}

Table 3. Income of respondents (living expenses)

\begin{tabular}{|c|c|c|c|c|c|}
\hline Income/yuan & Below & $2000-5000$ & $5000-8000$ & $8000-10000$ & above10000 \\
\hline Proportion & $40.3 \%$ & $37.31 \%$ & $14.93 \%$ & $5.97 \%$ & $1.49 \%$ \\
\hline
\end{tabular}

Table 4. Satisfaction of staying experience

\begin{tabular}{|c|c|c|c|c|c|c|}
\hline $\begin{array}{c}\text { Measurement } \\
\text { standard }\end{array}$ & $\begin{array}{c}\text { Accommoda } \\
\text { tion }\end{array}$ & $\begin{array}{c}\text { Service } \\
\text { quality }\end{array}$ & Price level & $\begin{array}{c}\text { Room layout } \\
\text { and } \\
\text { implementation }\end{array}$ & Security & $\begin{array}{c}\text { Cultural } \\
\text { characteristics }\end{array}$ \\
\hline Score & 4.14 & 4.32 & 4.04 & 4.32 & 4.25 & 4.28 \\
\hline
\end{tabular}

Tourist price sensitivity: Nowadays, the competition in the tourism industry is getting fierce day by day, causing homestay owners to focus on how to set reasonable prices in order to attract more tourists' attention. In Table 3, $40.3 \%$ of tourists have incomes of less than 2,000 yuan, and $37.31 \%$ of tourists have incomes of 2,000-5,000, which means that most tourists have incomes of less than 5,000 yuan, while the price of Yinquan homestay is $600-700$ one night, based on the comparison between tourist income and the price of homestays, and in this survey, the respondents' satisfaction with homestay prices is relatively low, only 4.04 , and only $46.27 \%$ of the respondents think the prices are cheap. This shows that tourists are still quite sensitive to prices.

\section{PROBLEMS EXISTING IN TOURISM DEVELOPMENT OF JINAN YINQUAN HOMESTAY}

\subsection{Supporting Facilities and Services Need to Be Improved}

The key to the operation of homestays relies on supporting facilities and high-quality services, so as to differentiate them from other homestays in the market and attract tourists. On the one hand, the supporting facilities of Yinquan homestay are not perfect, which brings inconvenience to some tourists. In the questionnaire, only $38.81 \%$ of the tourists thought that the transportation near the homestay was convenient, and $58.71 \%$ of the tourists thought that the room facilities needed to be upgraded. Among the 134 suggestions, 5 tourists clearly suggested that the homestay should build a parking lot. On the other hand, Yinquan homestay, like other homestays, provides only standardized services in terms of providing accommodation, simple meals, and consulting services for tourists. It cannot stand out from other homestays. At the same time, $39.8 \%$ of tourists suggested increasing service quality. However, the establishment of distinctive homestays is not a day's work. Homestay owners need to intensify innovation in the basic facilities, service quality, cultural atmosphere, and business philosophy of the homestay to form their own unique characteristics.

\subsection{Single Way of Publicity}

With the development of the tourism market, the homestay market has now entered an era where "the smell of wine can also be deep in the alleys". No matter how good the quality of the service and the distinctive homestays, they must rely on publicity to win the attention of tourists. In the questionnaire, $78.61 \%$ of tourists obtained information about homestays online, 
and only $38.61 \%$ of tourists learned about Yinquan homestay in Jinan. Secondly, the publicity method of Yinquan homestay is mainly based on the recommendation of WeChat public accounts, such as Qilu Weekly, Jinan Culture and Tourism Bureau and other public account platforms, and there are almost no other publicity methods. When we opened the search engine, most of them were booking pages for homestays. It was difficult to find promotional videos and materials about Yinquan homestay. In addition, after searching, Yinquan homestay does not have its own official Weibo, nor does it have a WeChat official account platform, which makes it difficult for interested tourists to know the information of the hotel in advance.

\subsection{Lack of Brand Building and Weak Attractiveness}

With the arrival of the new era, people's living standards are improving, and tourists pay more and more attention to the quality of homestays. When choosing homestays, the brand is also an important consideration. After all, the brand is a symbol and represents the quality, style and reputation of the homestay. It is a brand on the hearts of tourists. Yinquan homestay has just started. It is the owner of the homestay who invests and operates independently, without brand support, and has little influence. In addition, Jinan's old town homestay is highly competitive, so it is easy to be overwhelmed by the market. In the questionnaire, only $54.73 \%$ of tourists chose Yinquan homestay because of the brand. Therefore, Yinquan homwstay can consider cooperating with other homestays to build a strong brand and create a boutique homestay.

\subsection{The Cultural Connotation of Homestays Is not Deeply Explored}

A good homestay will dig deep into the cultural connotation of the homestay to give play to its unique charm and provide visitors with unforgettable experiences and memories. If you only provide standardized services, then the homestay is not different from the hotel. Therefore, nowadays homestays cannot only have accommodation functions. Those homestays with homogeneity, lack of characteristics, and insufficient cultural connotations will be eliminated by the market because they cannot meet the individual needs of tourists. Therefore, while realizing the function of "living", they must also provide some activities. , Allowing visitors to feel the unique local culture. In the questionnaire, $56.72 \%$ of tourists chose Yinquan homestay because of cultural connotation, and the overall cultural characteristics of the homestay was only 4.28 in the tourist experience score. Therefore, Yinquan homestay builds a spring culture, not only to allow tourists to taste the sweet spring water, but also to provide a wealth of activities so that visitors can fully experience the spring culture of Jinan.

\section{TOURISM DEVELOPMENT COUNTERMEASURES OF JINAN YINQUAN HOMESTAY}

\subsection{Improve Supporting Facilities and Services}

As a new-age industry, homestays develop rapidly, integrate with other industries, and have good economic benefits. The most important of these are the supporting facilities and services provided by the host. In terms of supporting facilities, in addition to solving the parking lot problem that most tourists are concerned about, Yinquan homestay can also pay attention to the following two aspects: the sanitation and safety of the hotel. Improve the cleanliness of the guesthouse rooms and provide fire extinguishers for each room. In addition, the service of Yinquan homestay has only reached a standardized level, and does not reflect the meticulousness and personalization. Therefore, Yinquan homestay should use big data to collect, sort and analyze the accommodation preferences of tourists, provide services based on tourists' preferences, and attract tourists with detailed services. For example, the owner of the hotel will remember the name of every visitor. , Calling out each other's name when the host and guest are communicating will bring each other closer and make visitors feel at home. Homestay owners should also pay attention to the continuity of services, pay attention to the maintenance of the relationship between tourists after consumption, send holiday or birthday wishes to tourists through mailboxes, or invite guests who have stayed in to participate in some activities, which will enhance the service of Yinquan homestay quality.

\subsection{Broaden Promotion Channels}

The attractiveness of Yinquan homestay is weak, partly because of its low publicity and single method. According to a survey of tourists, it is found that most tourists search for homestays through Internet platforms such as Ctrip.com and Tongcheng Yilong.com, and make mistakes in booking homestays online [5]. It can be seen that APP is the main platform for tourists to understand homestay information and make purchase decisions, and homestay owners are the main source of tourists. Therefore, Yinquan homestay should use the Internet to broaden its publicity channels, establish its Weibo and WeChat official account platforms, and release micro-films and short videos about the homestay to stimulate the sight and hearing of potential customers. Putting the propaganda pictures and videos of the homestay on the OTA platform, and adding a tourist exchange forum, can let the tourists who have stayed in the homestay publicity and improve the credibility. 


\subsection{Building a Homestay Brand}

The establishment of a unique and irreplaceable brand image for homestays is a key way to stand out in the market. Yinquan homestay lacks brand awareness and has little influence. Collective development is an important choice for brand building. In 2017, in the face of the high cost of individual homestays, low profitability, and the pressure of cultural and policy issues encountered in the development of homestays, Moganshan homestays actively explored and adopted the collective development method of homestays to reduce financial pressure, Concentrate on business. Jinan has a large number of homestays and small scales, and the services provided are similar. Yinquan homestay can combine with other styles of homestays and learn from this approach to create a well-known homestay service brand.

\subsection{Digging into the Cultural Connotation of Homestays}

The main purpose of tourists choosing homestay travel is to experience life in a different way, away from the hustle and bustle of the city, and immersively experience local daily cultural life. The cultural connotation of the homestay must be integrated into every aspect of the homestay, from the design of the house, the services provided to the activity experience of tourists, and the cultural connotation of the Yinquan homestay still stays at a shallow level. Yinquan homestay uses spring culture to create its own overall cultural atmosphere. In addition to reflecting on the layout of the homestay, it also needs to make a fuss about the experience project design, allowing tourists to participate in the experience of Jinan's local spring culture. For example, visitors can make tea in spring water by themselves, use character performances to let visitors understand spring culture, and even use VR and AI technology to let visitors experience spring water culture in depth. The owner of the homestay can also present the spring culture souvenirs to the visitors staying in the homestay, so that the visitors can not only feel the spring culture, but also "take away" the spring culture.

\section{CONCLUSION}

The development of homestay tourism involves a wide range of contents, and as an important part of the tourism process, it needs to be developed from multiple angles. This article only studies the Jinan Yinquan homestay from the perspective of tourists' perception, and puts forward feasible measures for some problems that arise. Due to time and ability reasons, there are still some problems. For example, the number of visitors to this article is limited, and the information obtained is also limited. Secondly, the experience satisfaction of homestays is only based on questionnaire surveys and online queries, and relevant content needs to be further enriched. In short, more and more attention has been paid to the tourism development of homestays. As long as the experience of the homestay is enhanced from the perspective of characteristics and personalization, the Yinquan homestay can stand out.

\section{REFERENCES}

[1] JOSEN D L, GUAN J J. Bed and breakfast lodging development in Mainland China: who is the potential customer $[\mathrm{J}]$. Asia Pacific journal of tourism research,2011,16(5):517-536.

[2] Lu Huijuan, Li Xiang. Research on the attractiveness of homestay tourism based on IPA analysis_-Taking the courtyard homestays in the core area of Beijing as an example[J]. Regional Research and Development,2020,39(01):112-117.

[3] Lu Shiju, Wu Hailun. Research on the Development of B\&B Tourism in Ethnic Areas under the Background of Targeted Poverty Alleviation[J]. Guizhou Ethnic Studies,2019,40(01):135-138.

[4] Zhang Miaoying. Short-term rentals for homestays are ushering in good news, and system construction must not lag behind [N]. China Tourism News, 2018-11-19(003).

[5] Fan Mengdan. Research on the relationship between tourist accommodation experience, tourism involvement, and behavioral intentions-Taking Xiamen B\&Bs as an example Fujian Agriculture and Forestry University [D]. Fujian Agriculture and Forestry University, 2017. 